\title{
Static Secondary Ionization Mass Spectrometry Detection of Cyclohexylamine on Soil Surfaces Exposed to Laboratory Air
}

\author{
G. S. Groenewold, J. C. Ingram, A. K. Gianotto, A. D. Appelhans, \\ and J. E. Delmore \\ Idaho National Engineering Laboratory, Idaho Falls, Idaho, USA
}

Cyclohexylamine (CHA) is a common indoor air contaminant, which rapidly adsorbs to aluminosilicate soil samples. Static secondary ion mass spectrometry was used to study soil samples exposed to both CHA and CHA- $d_{11}$, and the results showed (1) abundant $[\mathrm{M}+\mathrm{H}]^{+}$ and fragment ions that originated from $\mathrm{CHA},(2)$ an initial concentration of $\mathrm{CHA}$ equivalent to approximately 0.2 monolayer, and (3) a possible exchange reaction where excess $\mathrm{CHA}-d_{11}$ displaces CHA originally adsorbed to the surface. CHA was not removed from the surface by prolonged exposure to vacuum conditions $\left(5 \times 10^{-7}\right.$ torr), which indicates that CHA strongly adsorbs to aluminosilicate surfaces and should be expected as an endogenous surface contaminant where the chemical is used as a corrosion inhibitor. (f Am Soc Mass Spectrom $1996,7,168-172)$

$\mathrm{C}$ yclohexylamine (CHA) is a strong base that is used widely as a corrosion inhibitor, because it discourages scale formation and pipe deterioration in boiler systems that are used to heat and humidify facility air [1]. The compound is toxic at high exposure levels [2] and has been implicated as a causative of several deleterious health effects [1]. For this reason, the permissible exposure limit for CHA was established at $10 \mathrm{ppm} \mathrm{v/v}\left(40 \mathrm{mg} / \mathrm{m}^{3}\right)$ [3].

During the course of static secondary ion mass spectrometry (SIMS) applications studies of environmental samples, it was observed that CHA was a significant surface contaminant in the authors' laboratory, which is humidified by a boiler protected with CHA. This discovery prompted us to characterize the spectral signature of CHA on a soil sample that was under study in our laboratory. The ease with which CHA could be detected suggests that static SIMS may have utility to characterize environments exposed to contaminants that are airborne, but nonetheless strongly surface adsorptive [4]. Because this type of contaminant will partition between the air and environmental surfaces, a surface analysis such as SIMS would be very complementary to conventional analyses of airborne contaminants, which rely upon air sampling (these are routinely employed in industrial hygiene surveys). Notable examples of this latter approach have employed membrane [5] and solid sorbent enrichment, followed by gas chromatography (GC) detection [1].

Address reprint requests to Dr. Gary S. Groenewold, Idaho National Engineering Laboratory, P.O. Box 1625, Idaho Falls, ID 83415-2208.

\section{Experimental}

\section{Secondary Ion Mass Spectrometry Instrumentation}

The instrument used in these studies has been described in detail previously [6]; it uses $\mathrm{ReO}_{4}^{-}$at $10 \mathrm{keV}$ as the primary bombarding particle, which is produced by heating a ceramic that contains $\mathrm{Ba}\left(\mathrm{ReO}_{4}\right)_{2}$ in vacuum [7]. The ion gun was typically operated at 50 $\mathrm{pA}$, although variations of $\pm 20 \%$ commonly were observed over the course of a day. The focusing of the primary ion gun was adjusted so that the sample was just silhouetted on an image intensifier located behind the sample. Thus, most of the primary ion beam is directed onto the target to which the sample was taped. A typical acquisition required $36 \mathrm{~s}$ and a typical sample had a geometric area of about $0.08 \mathrm{~cm}^{2}$. Therefore, a typical dose was $1.1 \times 10^{11}$ ions $/ \mathrm{cm}^{2}$. This dose is substantially less than the commonly accepted static SIMS limit [8].

The secondary anions and cations were extracted alternately from the sample target region (pulsed extraction [6]), which mitigates charge buildup on the surface of the sample and permits near simultaneous acquisition of the anion and cation spectra. The ratio of [time extracting cations]/[time extracting anions] was 5.0 and the total period for a single pulsed extraction sequence was $65 \mathrm{~ms}$, divided as follows: cation extraction, $50 \mathrm{~ms}$; electronic settle time, $2.5 \mathrm{~ms}$; anion extraction, $10 \mathrm{~ms}$; electronic settle time, $2.5 \mathrm{~ms}$. This sequence was repeated for each 0.2-u step of the scan of the quadrupole mass spectrometer, which was scanned from 10 to $130 \mathrm{u}$. The quadrupole was a 2-2000-u 
instrument, manufactured by Extrel (Pittsburgh, PA) and modified in our laboratory. The quadrupole was tuned for unit mass resolution and optimum sensitivity for $m / z 198^{+}$in the SIMS spectrum of tetrahexyl ammonium bromide [9].

Ion abundances were expressed as a fraction of the total ion abundance from $\mathrm{m} / \mathrm{z} 10$ to 120 . The precision of the relative ion abundance measurements was assessed by calculation of the percent standard deviation for several of the salient ions for a set of five soil analyses performed on different days. Percent relative standard deviation (\% RSD) values of $30-60 \%$ were typical and, in general, the ions that had the lowest mean abundance also had the poorest precision. The best precision was calculated for $m / z 41^{+}$, which is usually the base peak in the cation spectrum. Several factors which include sample inhomogeneity, variable atmospheric contaminant concentrations (especially for $\mathrm{CHA}$-derived ions at $100^{+}, 83^{+}$, and $\left.18^{+}\right)$, and variable sample preparation (i.e., incomplete coverage of the double-sided tape), likely contribute to the imprecision. We note that the \% RSD values measured here are consistent with previous experience in our laboratory (i.c., basalt samples contaminated with tri-n-butyl phosphate) [10].

\section{Sample Origin and Composition}

The soil samples used in the present experiments originated from a Raritan, NJ site. The soil was sieved and the $0.25-\mathrm{mm}$ fraction was used for the studies. This fraction had a surface area of $2.2 \mathrm{~m}^{2} / \mathrm{g}$, as determined by using nitrogen adsorption (Brunauer-EmmettTeller surface area determination, Micromeritics, Gemini model 2360) [11]. An approximate composition of the soil was determined to be $\left(\mathrm{Si}_{4} \mathrm{AlO}_{11}\right)^{-3}$, which in nature is balanced by Group I cations (present at approximately 1 at.\%), calcium, transition metals, and protons. This is a typical aluminosilicate soil material. This elemental composition information was acquired by using energy dispersive $x$-ray spectroscopy (EDS). The details of this procedure are identical with those previously published for other samples [10].

\section{Sample Exposure and Preparation for Secondary Ion Mass Spectrometry Analysis}

Soil samples were exposed to CHA when they were brought into the laboratory atmosphere. The concentration of CHA in the lab air was determined to be in the 100-300-ppb range, as determined by air sampling conducted by the Idaho National Engineering Laboratory industrial hygiene organization, by using silica sorbent tubes. The tubes subsequently were analyzed by using thermal desorption with GC, following NIOSH method 221 [12].

Soil samples were exposed to $\mathrm{CHA}-d_{11}$ by placing 15-50 mg inside of a $40-\mathrm{cm}^{3}$ jar, near one edge. A droplet (10-50 $\mu \mathrm{L})$ of a $\mathrm{CHA}^{-} d_{11}$ standard solution (see following text) was then placed in the jar, on the edge opposite the location of the soil. Care was taken so that the soil did not become wet. The jar was then covered with a glass plate, and placed in an oven at $100^{\circ} \mathrm{C}$ for $20-30 \mathrm{~min}$, during which time the droplet of standard solution evaporated. The jar was then allowed to cool, whereupon the gaseous $\mathrm{CHA}-d_{11}$ adsorbed onto the soil. Adsorption onto the glass walls of the jar and cover also occurs, but the combined surface areas of these items is only $6-20 \%$ of the surface area of the soil. This consideration and the SIMS spectra of the soil and the glass walls of the jar lead to the reasonable conclusion that most of the $\mathrm{CHA}_{-11}$ adsorbs to the soil sample. Surface coverages were estimated by calculation of the area occupied by the CHA (number of molecules in the jar $\times 24 \AA^{2} /$ molecule [13]), and then division by the surface area of the sample (soil mass $\times$ surface area/gram).

Soil samples were prepared for analysis by attachment to a stainless steel target by using double-sided tape. Typical tape size was $2 \times 4 \mathrm{~mm}$, which accommodates about $1 \mathrm{mg}$. Once attached, the samples are then directly admitted to the SIMS instrument via the insertion lock.

Deuterium substitution of CHA exchangeable protons was evaluated by analyzing a gold-plated steel target, which was acidified with $\mathrm{HCl}$, then allowed to stand in the lab atmosphere. Under these conditions, the gold target was coated with $\mathrm{CHA}$. Two microliters of liquid $\mathrm{D}_{2} \mathrm{O}$ were then applied to this target, which was then allowed to air dry prior to analysis.

\section{Chemicals and Standards}

Cyclohexylamine was procured from Aldrich Chemical Co. (Milwaukee, WI) and cyclohexylamine- $d_{13}$ was procured from Cambridge Isotope Laboratories (Woburn, MA). Primary standards of CHA- $d_{11}(1 / 10$, $1 / 100 \mathrm{v} / \mathrm{v}$ ) were made by using methanol as the solvent to facilitate initial dissolution. Soil samples were exposed to secondary standards (to $1 / 10^{6}, \mathrm{v} / \mathrm{v}$ ), which were made by dilution of the primary standards with water. During these dilutions, the amino deuterons of $\mathrm{CHA}-d_{13}$ were exchanged to form CHA$d_{11}$. The concentration of the standard used was chosen such that the volume of the standard solution in the jar was manageable $(10-50 \mu \mathrm{L})$.

\section{Results and Discussion}

A typical static SIMS spectrum of a soil sample (Figure 1a) contained abundant ions at odd masses that correspond to $\mathrm{C}_{n} \mathrm{H}_{2 n+1}^{+}, \mathrm{C}_{n} \mathrm{H}_{2 n-1}^{+}, \mathrm{C}_{n} \mathrm{H}_{2 n-3}^{+}$, and so forth. The precise origin of these peaks is unknown, but is thought to be airborne paraffinic compounds that adsorb onto most if not all sample surfaces. Aromatic ions were observed at $m / z 91$ and 77 , and $m / z 18$ has been attributed to $\mathrm{H}_{2} \mathrm{O}^{+}$[14]. In addition, ions that 
a
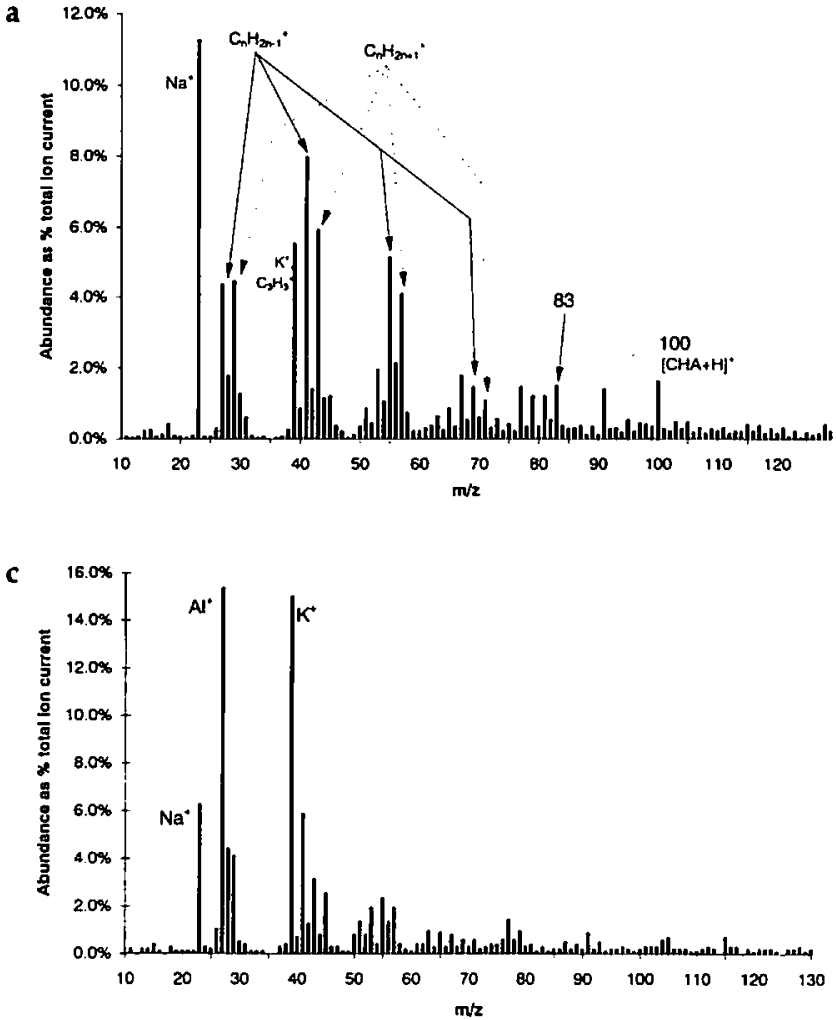

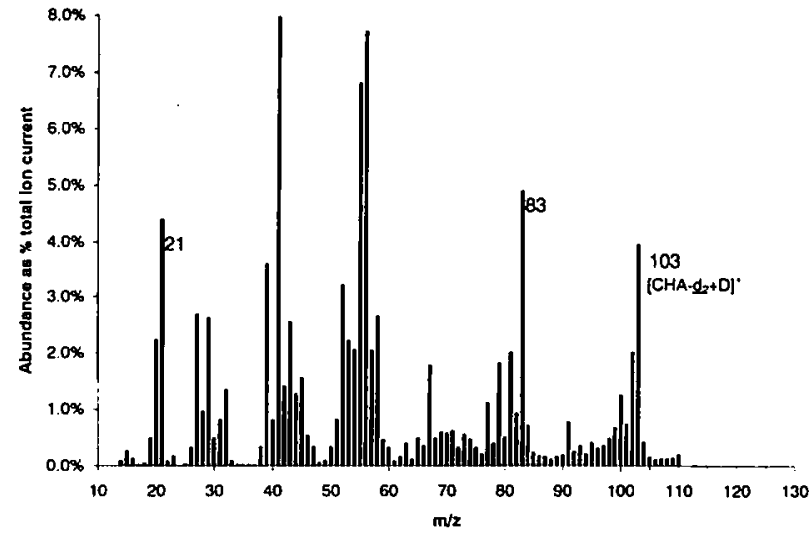

d

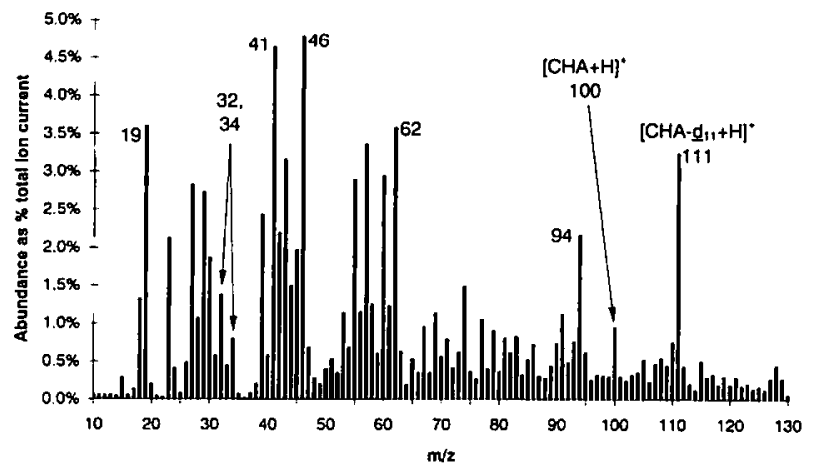

Figure 1. Cation SIMS spectra of (a) Raritan soil (aluminosilicate) exposed to laboratory air that contains a low concentration of cyclohexylamine (CHA), (b) $\mathrm{CHA}$ adsorbed to a gold surface treated with $\mathrm{D}_{2} \mathrm{O}$, (c) Raritan soil evacuated for $64 \mathrm{~h}$ and then bombarded for $60 \mathrm{~min}$., and (d) Raritan soil exposed to gas-phase CHA- $d_{11}$.

originate from the aluminosilicate soil sample are observed: $m / z 23$ corresponds to $\mathrm{Na}^{+}$and ions at 27,28 , 39 , and 56 certainly contain components that correspond to $\mathrm{Al}^{+}, \mathrm{Si}^{+}, \mathrm{K}^{+}$, and $\mathrm{Fe}^{+}$, in addition to isobaric organic ions. All of the above-mentioned ions are routinely observed in static SIMS analyses of this type of sample $[10,14]$.

In contrast, the ion at $m / z 100$ was unusual compared to static SIMS spectra that have been reported previously [14], which motivated an investigation to determine its composition and origin. It was reasoned that $m / z 100$ most likely contained an odd number of $\mathrm{N}$ atoms, given the known propensity of SIMS for the production of even-electron ions [15].

A gold target that previously was coated with $\mathrm{CHA}$ was treated with $2-\mu \mathrm{L} \mathrm{D}_{2} \mathrm{O}$, allowed to dry, and then analyzed for the purpose of identification of exchangeable protons (Figure 1b). The shift of $m / z 100$ to $m / z$ 102 and 103, which indicated the presence of three exchangeable protons, was consistent with a primary amine. The fact that all of the intensity was not shifted to 103 likely was due to incomplete isotopic substitution that arises from the presence of other proton sources on the gold surface. Similar attempts to replace the amino protons of CHA adsorbed to soil were only partially successful; this may also indicate the presence of strongly bound protons on the soil surface, which do not readily exchange, but do participate in protona- tion of the adsorbate. On the gold target, deuterium substitution shifted the $m / z \quad 18$ ion to $m / z 20$ and 21 (but not to 22), which indicates that the ion is primarily $\mathrm{NH}_{4}^{+}$, as opposed to $\mathrm{H}_{2} \mathrm{O}^{+}$, which would produce only $m / z 19$ and 20 upon deuteration. Furthermore, the D-substitution of the $\mathrm{NH}_{4}^{+}$fragment (to produce $\mathrm{ND}_{3} \mathrm{H}^{+}$at $m / z 21$ ) strongly suggests a primary amine, which upon protonation would eliminate a neutral alkene via rearrangement of a nonexchangeable aliphatic proton to the deuterated ammonium moiety. An alternative explanation would be the presence of ammonium on the mineral surface, but this is not preferred, because no $m / z 22\left(\mathrm{ND}_{4}^{+}\right)$is observable in the deuterated experiment. We thus concluded that the likely composition of the contaminant was $\mathrm{C}_{6} \mathrm{H}_{11} \mathrm{NH}_{2}$ and that cyclohexylamine (CHA) was a primary candidate, although its origin was yet undetermined.

It was later learned that cyclohexylamine $(\mathrm{CHA})$ was added to the steam boilers of the laboratory as a corrosion inhibitor and that the steam was used to humidify the laboratory air during the winter months (September to May in Idaho). Twenty samples of laboratory air were collected on four different days in December and January, and three of the samples were determined to have CHA concentrations of 300,500, and $1300 \mathrm{ppb}$ (using GC; see Experimental). CHA was not detected in the remaining 17 samples (the detection limit was $100 \mathrm{ppb}$ ). These results reflect the sur- 
prising adsorptive tendency of CHA: many surfaces in the laboratory will develop a substantial coating in a short period of time, even though the atmospheric contamination is low. CHA will adsorb to other surfaces in addition to minerals. Cyclohexylammonium chloride crystals, identified by NMR, were observed to form on the neck of a bottle of concentrated $\mathrm{HCl}$.

The implication of CHA as the source of the $\mathrm{m} / \mathrm{z}$ 100 ion was confirmed by removal of the CHA from the surface of a soil sample and then intentional re-exposure of the sample to lab air that contained CHA. Initial attempts to remove the $\mathrm{CHA}$ by leaving a soil sample in the vacuum housing of the instrument were unsuccessful: a SIMS spectrum collected after $64 \mathrm{~h}$ was nearly identical with the spectrum initially recorded. However, it was found that the CHA could be ablated from the sample surface by using the primary ion beam. After a dose of approximately $1.4 \times 10^{13}$ ions $/ \mathrm{cm}^{2}(1 \mathrm{~h}$ of bombardment at $50 \mathrm{pA}$ ) the CHA signal had disappeared (Figure 1c). In this spectrum, the abundances of $\mathrm{m} / z 27$ and 39 were enhanced; these ions are assigned $\mathrm{Al}^{+}$and $\mathrm{K}^{+}$, and the enhancement is interpreted in terms of removal of organic contamination from the surface. The abundance of $m / z 100$ was negligible.

When the ablated soil sample was exposed to the lab air for $5 \mathrm{~s}$, the CHA ions reappeared and the SIMS spectrum was nearly identical with that initially recorded. Subsequently, the sample was exposed to the head space above a small vial of neat CHA for $15 \mathrm{~s}$ : the resulting SIMS spectrum contained $\mathrm{CHA}$ ions, which were very abundant. Several of the ions in the hydrocarbon ion envelopes also increased in abundance (viz. $m / z 83, \mathrm{C}_{6} \mathrm{H}_{11}^{+}$), which indicated that they also originated from CHA.

Deuterated $\mathrm{CHA}$ ( $\mathrm{CHA}-d_{11}$ ) was applied to the soil surface to elucidate the SIMS fragmentation chemistry and to estimate the surface concentration. Experimentally, the most straightforward means to apply $\mathrm{CHA}-d_{11}$ was to expose the soil to vapor (see Experimental). This method resulted in CHA- $d_{11}$-exposed samples that were used to generate reproducible SIMS spectra. Attempts to apply $\mathrm{CHA}-d_{11}$ by exposure of the soil to aqueous solutions were not reproducible, which may reflect unfavorable partitioning between the soil surface and the water. Contaminant partitioning between water and soil is known to have a large bearing on adsorption of organophosphates to soil [16] and would be expected to strongly influence amines. Variables that control adsorption in heterogeneous CHA$d_{11} / \mathrm{H}_{2} \mathrm{O} /$ soil systems are not understood yet.

Secondary ion fragmentation chemistry of CHA was discerned much more easily in the spectra of $\mathrm{CHA}-d_{11}$ on soil, because the masses of the fragment ions are shifted away from the indigenous hydrocarbon background (Figure 1d). As anticipated, the $[\mathrm{M}+\mathrm{H}]^{+}$was shifted from $m / z 100$ to 111 , which is consistent with the presence of 11 nonexchangeable deuterium atoms in the cyclohexyl moiety. Abundant fragment ions are observed, which contrasts with minimal fragmentation observed in chemical ionization spectra (reagent gases used were $i$-butane, ethylene diamine, and ethanolamine) [17]. The $m / z 94$, which corresponds to $\mathrm{C}_{6} \mathrm{D}_{11}^{+}$, arises by loss of $\mathrm{NH}_{3}$ from [CHA- $\left.d_{11}+\mathrm{H}\right]^{+}$. Ion compositions proposed for other masses (Figure 2) include only even-electron possibilities [15] and assume that extensive ammonium-ring $H / D$ scrambling does not occur. This assumption is supported by the observation of only $\mathrm{NH}_{3} \mathrm{D}^{+}$. If $\mathrm{H} / \mathrm{D}$ scrambling occurred, then $\mathrm{NH}_{2} \mathrm{D}_{2}^{+}, \mathrm{NHD}_{3}^{+}$and perhaps $\mathrm{ND}_{4}^{+}$would be expected. $\mathrm{NH}_{3} \mathrm{D}^{+}$indicates that $\mathrm{NH}_{4}^{+}$is formed via a unimolecular process that involves the transfer of a ring proton to the ammonium moiety. This conclusion is in accord with the observation of $\mathrm{ND}_{3} \mathrm{H}^{+}$.in the spectrum of $\mathrm{C}_{6} \mathrm{H}_{11} \mathrm{ND}_{3}^{+}$(see preceding text).

The surface concentration of $\mathrm{CHA}-d_{11}$ was varied to estimate the quantity of unlabeled CHA present on the soil surfaces. Subsequent to SIMS analyses, abundances of $[\mathrm{CHA}+\mathrm{H}]^{+}$and $\left[\mathrm{CHA}-d_{11}+\mathrm{H}\right]^{+}$were plotted against the quantity of $\mathrm{CHA}-d_{11}$, expressed in terms of monolayer coverage (Figure 3 ). The sum of the abundance of the $\left[\mathrm{CHA}+\mathrm{H}^{+}\right.$and $\left[\mathrm{CHA}-d_{11}+\right.$ $\mathrm{H}^{+}$was observed to slowly increase as more $\mathrm{CHA}-d_{11}$ was admitted to the system. At the same time, the abundance of $\mathrm{Na}^{+}$slowly decreased. These observations are consistent with the adsorbance of additional CHA- $d_{11}$ onto the surface of the soil.

At a CHA- $d_{11}$ concentration that corresponds to about 0.2 monolayer, the curve for $m / z 11$ [ [CHA- $d_{11}$ $+\mathrm{H}]^{+}$crosses that for $100[\mathrm{CHA}+\mathrm{H}]^{+}$. The surface concentrations of the unlabeled and $d_{11}$ compounds are approximately equal at this point. Because the abundance of $\left[\mathrm{CHA}+\mathrm{H}^{+}\right.$did not appreciably decrease up to this $\mathrm{CHA}-d_{11}$ concentration, the surface concentration of adventitious CHA on unmodified soil in the lab was estimated to be about 0.2 monolayer. At higher $\mathrm{CHA}-d_{11}$ concentrations, the $\left[\mathrm{CHA}-d_{11}+\mathrm{H}\right]^{+}$ abundance increases, as would be expected. Conversely, the abundance of the $[\mathrm{CHA}+\mathrm{H}]^{+}$decreases and we postulate two possibilities for this behavior:

1. CHA- $d_{11}$ displaces CHA (in addition to occupying additional surface sites). It may be that the heat used to facilitate volatilization of the standards also serves to remove some of the adsorbed CHA.

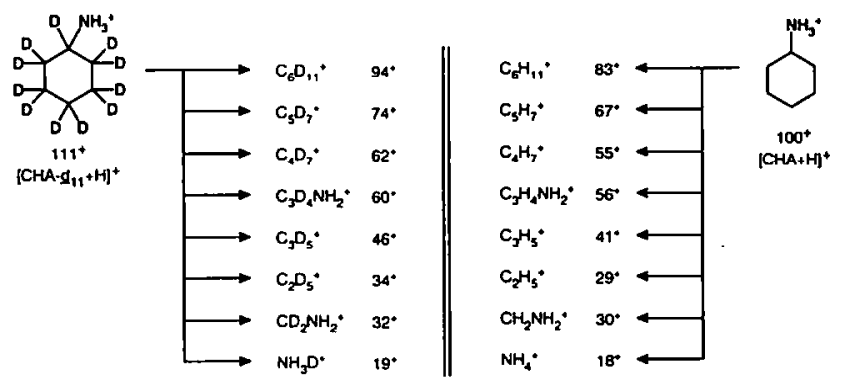

Figure 2. Fragment cations observed in the SIMS spectrum of $\mathrm{CHA}-d_{11}$ and corresponding cations that originate from $\mathrm{CHA}$. 


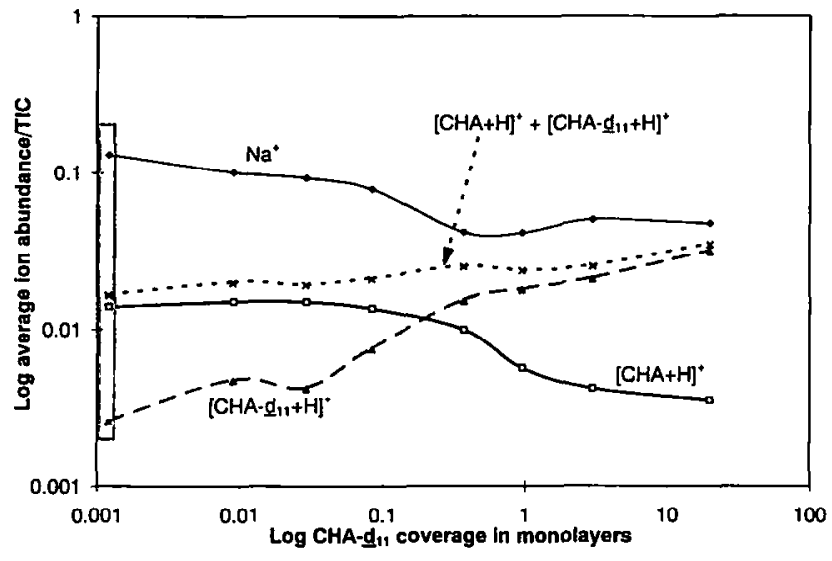

Figure 3. Average cation abundances/total cation current (TIC) plotted versus quantity of $\mathrm{CHA}-d_{11}$ used to expose soil, expressed in monolayers. Note that average abundances plotted at 0.0012 monolayer are actually data from analyses of soil not exposed to $\mathrm{CHA}-d_{11}$; they are included on this chart for comparison purposes. The 0.0012 monolayer value is arbitrary.

2. CHA is swamped by CHA- $d_{11}$ and the probability of CHA ionization decreases. The cause for the decrease in $[\mathrm{CHA}+\mathrm{H}]^{+}$is an open question.

The fact that the aluminosilicate mineral surface is not covered exhaustively with atmospheric CHA is consistent with the concept that there are several types of adsorptive sites, which have varying affinities for the compound. Inhomogeneous surface chemistry would be anticipated for a natural material like soil. If this is the case, then those sites that are weakly adsorptive may not be covered until an excess of CHA is present, as in the case of the higher CHA- $d_{11}$ exposures.

\section{Acknowledgment}

Funding support of the U.S. Department of Energy, Office of Health and Environmental Research, is gratefully acknowledged.
The authors also are indebted to Marnie Cortez for assistance with sample preparation and data acquisition, to Dick Roblee and Scott Marko for the atmospheric CHA measurements, and to Bob Fox for helpful discussion.

\section{References}

1. Orlando, R. A.; Lao, Y. J. J. Environ. Health 1993, 56, 6-9.

2. (a) Waltrous, R. M.; Schulz, H. N. Industrial Medicine and Surgery 1950 19, 317-320; (b) Mallette, F. S.; Von Haam, E. Am. Med. Assoc. Arch. Ind. Hygiene Occupational Med. 1952, 5 , 311-317.

3. Code of Federal Regulations; Title 29, Part 1910.1000, Air Contaminants; U.S. Department of Labor Occupational Safety and Health Administration; Washington, DC, 1989.

4. Billiet, H. A. H. J. Chromatogr. Library, 1992, 51B, B-583-B-595.

5. Gronberg, L.; Lovkvist, P.; Jonsson, J. A. Chromatographin 1992, 33, 77-82.

6. Appelhans, A. D.; Dahl, D. A.; Delmore, J. E. Anal. Chem. 1990, 62, 1679-1686.

7. (a) Delmore, J. E.; Appelhans, A. D.; Peterson, E. S. Int. /. Mass Spectrom. Ion Processes 1991, 108, 179-187; (b) Delmore, J. E.; Appelhans, A. D.; Peterson, E. S. Int. J. Mass Spectrom. Ion Processes 1995, in press.

8. Briggs, D.; Hearn, M. J. Vacuum 1986, 36, 1005-1010.

9. Winger, B. E.; Hand, O. W.; Cooks, R. G. Int. J. Mass Spectrom. Ion Processes 1988, 84, 89-100.

10. Groenewold, G. S.; Ingram, J. C.; Delmore, J. E.; Appelhans, A. D. J. Am. Soc. Mass Spectrom. 1995, 6, 165-174.

11. Adamson, A. W. Physical Chemistry of Surfaces; Wiley: New York, 1990, p 609.

12. NIOSH Manual of Analytical Methods, 3rd ed.; U.S. Department of Health and Human Services: Cincinnati, 1984.

13. Adamson, $\Lambda$. W. Physical Chemistry of Surfaces; Wiley: New York, 1990, p 436.

14. Benninghoven, A. Surface Sci. 1973, 35, 427-457.

15. Pachuta, S. J.; Cooks, R. G.; Cliem. Rev. 1987, 87, 647-669.

16. Kingery, A. F.; Allen, H. E., Toxicol. Environ. Chem. 1995, 47, 155-184.

17. Bowen, D. V.; Field, F. H. Org. Mass Spectrom. 1974, 9, 195-203. 